\title{
Techno-economic analysis for the assessment of heat pump integration in a real poly- generative energy district
}

\author{
Stefano Barberis ${ }^{(1),{ }^{*}}$, Paola Robello ${ }^{(1)}$, Diego Rattazzi ${ }^{(2)}$ Massimo Rivarolo ${ }^{(2)}$, Daria \\ Bellotti $^{(2)}$, Loredana Magistri ${ }^{(2)}$ \\ ${ }^{1}$ RINA Consulting S.p.A., via Liri 27, 16145 Genoa, Italy \\ ${ }^{2}$ Thermochemical Power Group, University of Genoa, Via Montallegro 1, 16145 Genoa, Italy
}

\begin{abstract}
The present research study aims at analysing technical and economic feasible solutions for heat pumps integration in energy districts for polygeneration purpose and particularly to store excess of electricity via Power-to-heat schemes considering that, from previous researchers' works, thermal storage has been identified as the most remunerative and easy to handle storage technology to maximise self-consumption in polygeneration grids. This technology is already developed and currently employed for conditioning of residential, commercial and industrial buildings. However, studies regarding the analysis of heat pumps' integration in energy districts for distributed generation are still limited. The potential advantages of its employment in this context are fuel savings, a lower emission level and the possibility to couple it with local renewable energy sources (i.e. solar panels, wind turbines) and traditional generators (i.e. engines, micro gas turbines) in order to increase flexibility in operational terms. In this paper, a performance analysis of the poly-generation energy district installed at the University of Genoa Campus, located in Savona, is analysed throughout a whole year: the model is implemented using a dedicated software tool, developed by Thermochemical Power Group. Different solutions for the integration of the heat pump, including size optimization, are investigated, considering the real data related to the University of Genoa Campus: the final aim of the analysis is to determinate the best operational strategy, minimizing variable costs (i.e. fuel) and evaluating the economic feasibility of heat pump installation in the energy district. This work has been also redacted as a preliminary analysis for solar-coupled HP integration (from a optimized management point of view) to be performed in the demonstration campaign of H2020 ENVISION Project", where both RINA Consulting and University of Genova collaborate.
\end{abstract}

\section{Introduction}

One of the most important challenges of our society is related to the production of energy, adopting more and more clean and sustainable methods. As energy demands have grown more and more in the last century, the impact of anthropogenic activities in terms of CO2 and pollutant emissions has increased as well. In the last years, many approaches have been proposed to face these environmental problems, improving the use of energy resources and increasing efficiency. Recently, after the 2015 Paris Climate Conference [1], the European Union set the energy policy targets for year 2030, to reduce by $40 \%$ the emissions of greenhouse gases compared to 1990 levels, to increase by $30 \%$ the energy efficiency

* http://www.energy-envision.eu/ - This project is supported by the European Commission under the H2020 Framework Programme GA 767180 
compared to the business as usual scenario and to reach $32 \%$ of RES share on total energy consumptions [2]. These ambitious goals can be achieved by adopting new strategies for energy production and distribution, also maximising Renewable production at building level as promoted by $\mathrm{H} 2020$ ENVISION project. Smart grids and poly-generative energy districts represent one of the most interesting solutions in this sense. Energy districts are characterised by the presence of technologies for CHP (Combined Heat and Power) production and by renewable generators, employing the available local RES (Renewable Energy Sources . i.e. wind, solar) [3]. Since the different energy demands (electrical, thermal, etc.) have different profiles and peaks at different times, energy storage systems (both at electric and thermal level) represent a strategic solution in order to manage the demands, increasing the system's efficiency [4][5] and stimulating a mutual benefit interaction between the management of energy demands (electric/thermal). Since poly-generative districts are usually characterized by different kind of generators, including not programmable ones (PV, wind turbines, etc.), a control strategy is necessary as well in order to optimize the management of the grid [6] and maximise local renewable production.

In this research work, the Smart Poly-generation Microgrid (SPM) of Savona at University of Genoa is investigated: the SPM represents an example of a poly-generative district, where different kind of generators are installed. More in detail, the SPM includes 4 mGTs (micro-gas turbines - for a total capacity of $260 \mathrm{kWe}$ and about $440 \mathrm{kWt}$ ), an ICE (Internal Combustion Engine - $20 \mathrm{kWe}, 467 \mathrm{kWt}$ ), PV solar panels $(77 \mathrm{kWe}$ ) and a boiler $(500 \mathrm{kWt})$ [5]. The SPM includes also a Thermal Energy Storage (TES), with a capacity of 10,000 litres, providing thermal energy as hot water [5]. The SPM is fed by natural gas and it is connected with the electrical grid.

The aim of the present work is to study the installation of a heat pump (HP) in the district, substituting the boiler, evaluating the performance of the solution from both an energetic and economic standpoint also evaluating how simple power to heat schemes and interaction between electric/thermal demand management strategies can be mutual beneficial thanks to $\mathrm{HP}+\mathrm{TES}$ exploitation. In order to perform the analysis, the management strategies of the SPM in the two configurations (with the boiler and with the heat pump) are investigated throughout a thermo-economic time-dependent approach, employing the W-ECoMP tool, developed by the Thermochemical Power Group at University of Genoa [7]. The software allows for optimizing both the size of the heat pump and the management of the different generators and of the energy storage in the SPM: the final aim is to determine the best strategy in order to minimize annual costs, fulfilling the energy (electrical and thermal) demands that are the constraint of the problem. More details about W-ECoMP are reported in [5][8][9]. At the end of the analysis, a comparison between the two solutions will be presented.

\section{Case studies}

Considering the SPM of Savona and its electrical and thermal loads, two different configurations are simulated using W-ECoMP software:

1. Configuration with boiler (Case A)

2. Configuration with HP (Case B)

The first studied scenario consists in the reference case, a state-of-the-art representation (Figure 1). In this case a natural gas boiler is used in order to cover the thermal demand that the CHP units cannot satisfy. This scenario is simulated in order to have base data to be compared with Heat Pump applications (Figure 2). 


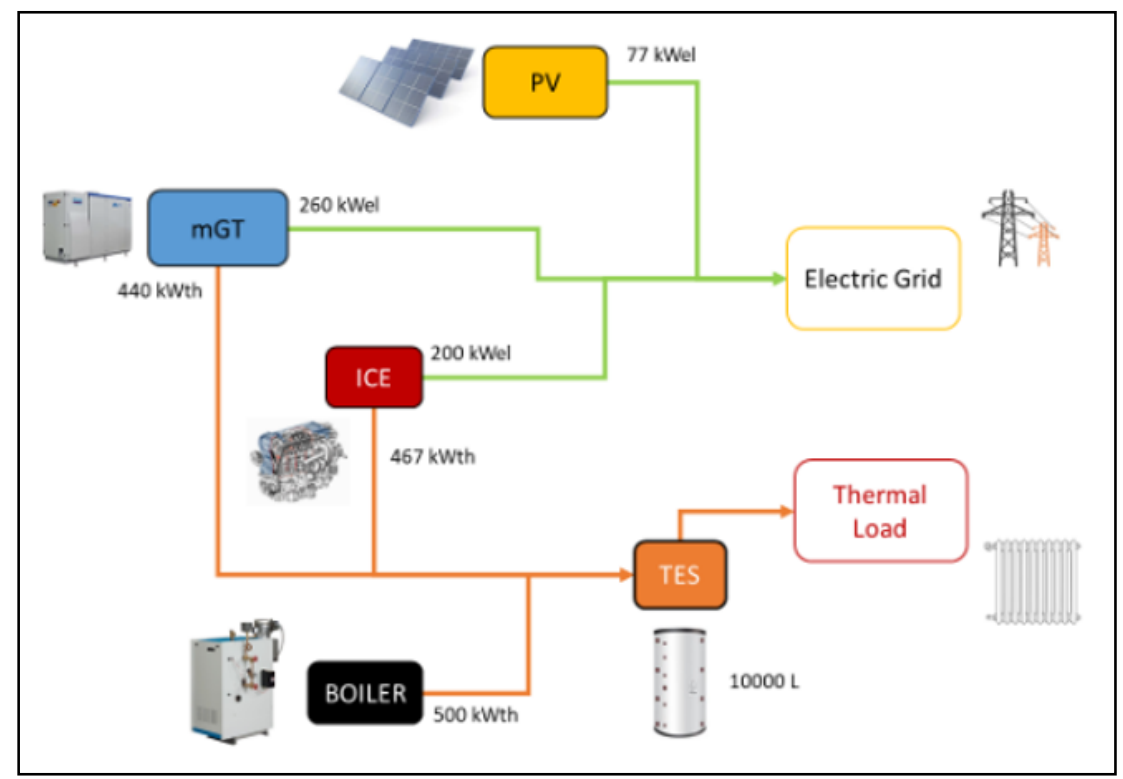

Fig. 1. Configuration with boiler (case A)

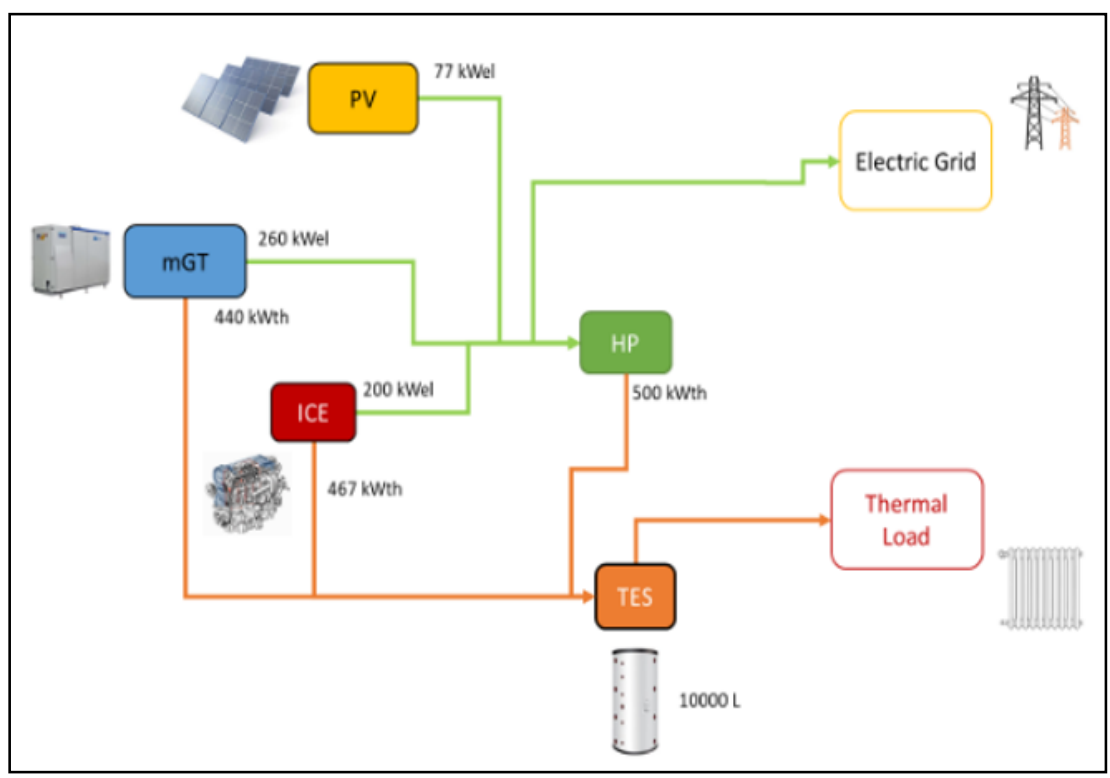

Fig. 2. Configuration with HP (case B)

The Case A results are reported for representative day of winter and summer season in Fig. 3 and Fig.4Error! Reference source not found. 

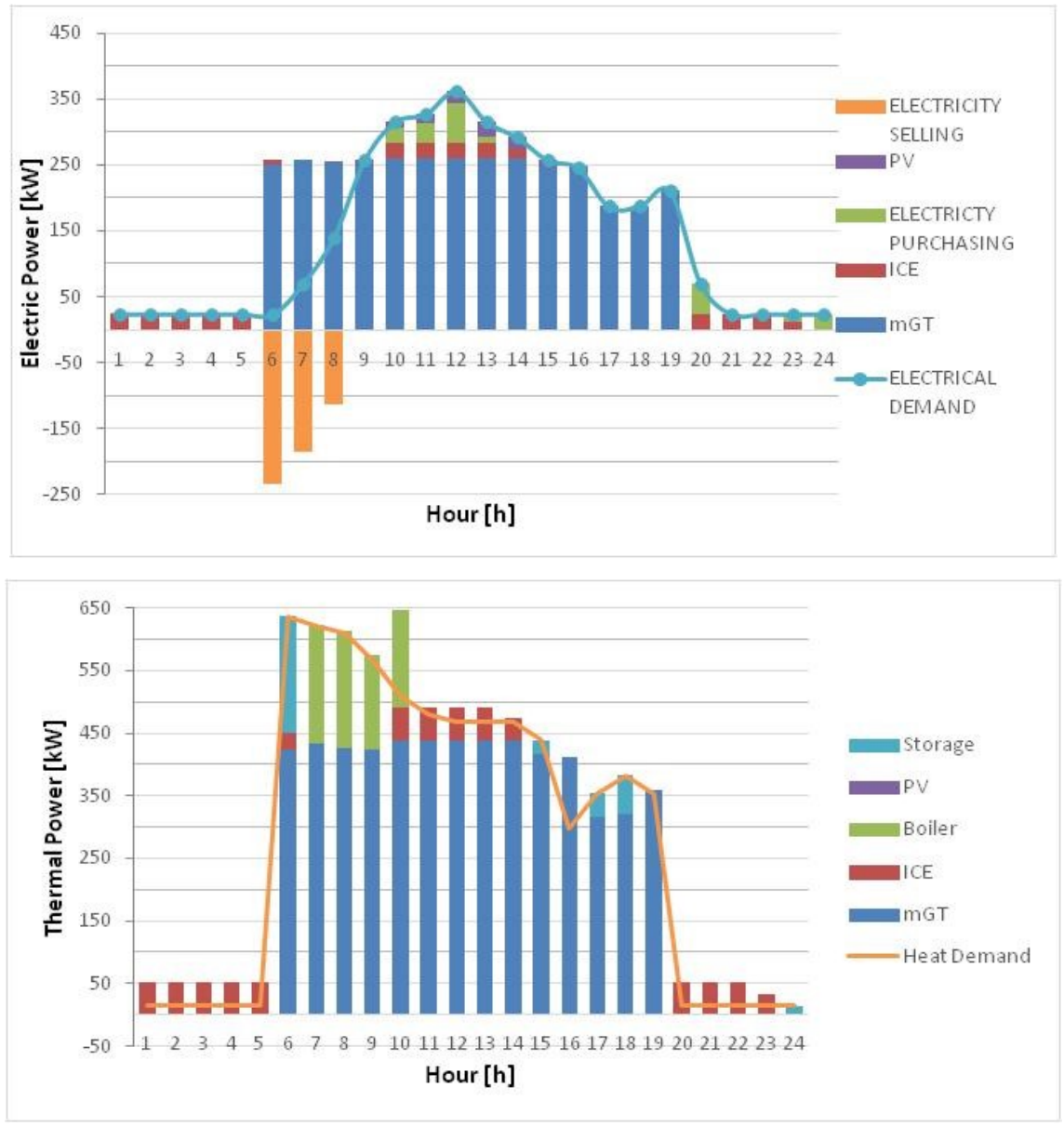

Fig. 3 Scenario A - Winter Time typical Electrical (Above) and Thermal (below) Demand

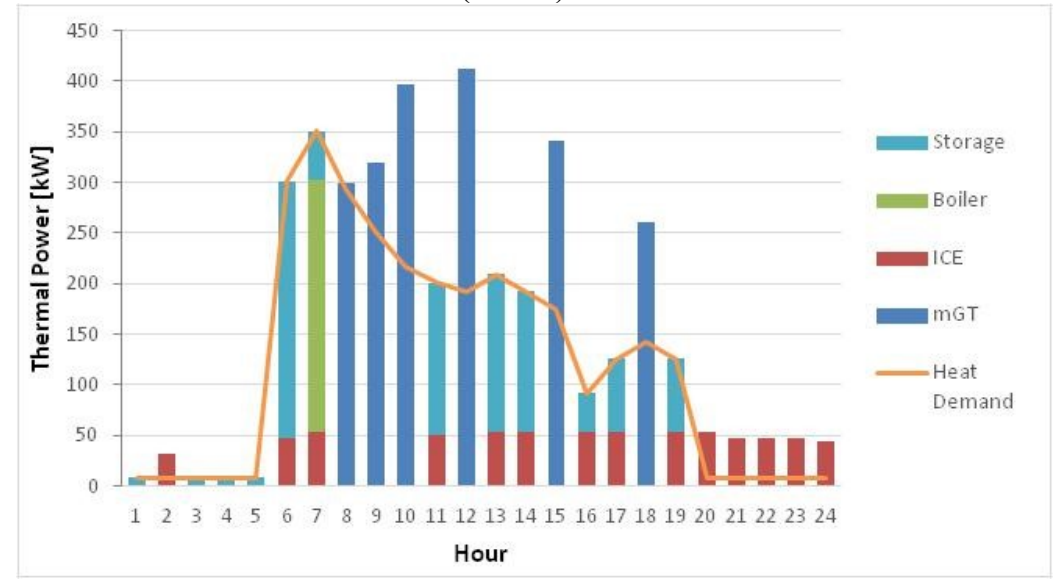




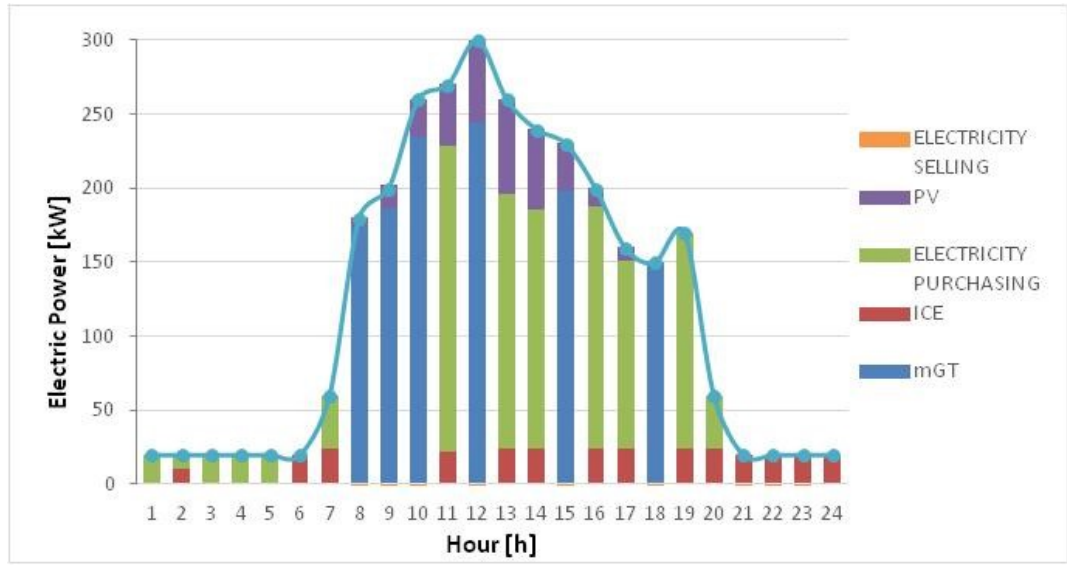

Fig. 4 Scenario A - Summer Time typical Electrical (Above) and Thermal (below) Demand)

Looking at Fig. 3, the system management strategy is quite predictable: the storage behaves like a buffer, filling in during night periods (using ICEs for covering electric demand) and covering peaks in the thermal demand. Unfortunately, the storage load is extinguished already in the early morning, therefore an intensive use of boiler is required during the rest of the day. In summer (Fig. 4), boiler use is limited to a very short period as thermal demand is lower and it can be easily covered using the CHP units and the TES.

The next step consists into the substitution of the boiler with an air to water Heat Pump electrically supplied by local electric production (PV and CHP units). This configuration allows to an increase of electrical demand and a more efficient heat production. The calculation, performed by the high level optimization algorithm in $\mathrm{W}-\mathrm{ECoMP}$, proposed an heat pump with a thermal size of $350 \mathrm{kWt}$.

This size allows a larger amount of electricity sold to the National grid (although reduced compared to the currently layout with a traditional gas boiler, Figure 2), particularly in winter periods when the CHP units coupled with the storage can cover easily the heat demand; furthermore the operating period in nominal conditions is enlarged for CHP units (Figure 5). In warm periods the storage (Figure 6) is more used coupled with the CHP units than with the heat pump as happened in winter period, so mGTs are more used to satisfy the thermal demand and heat pump reduces its contribution.

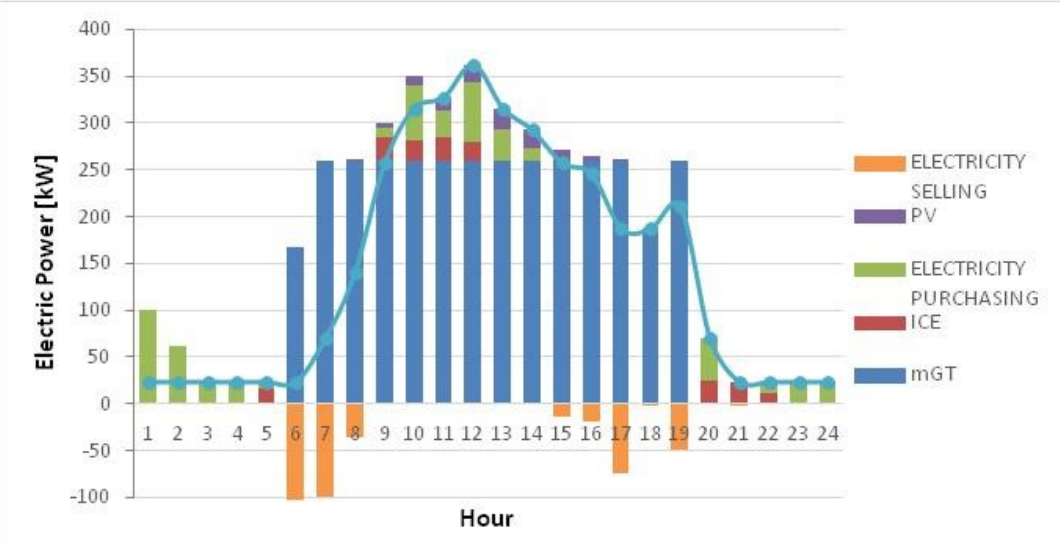




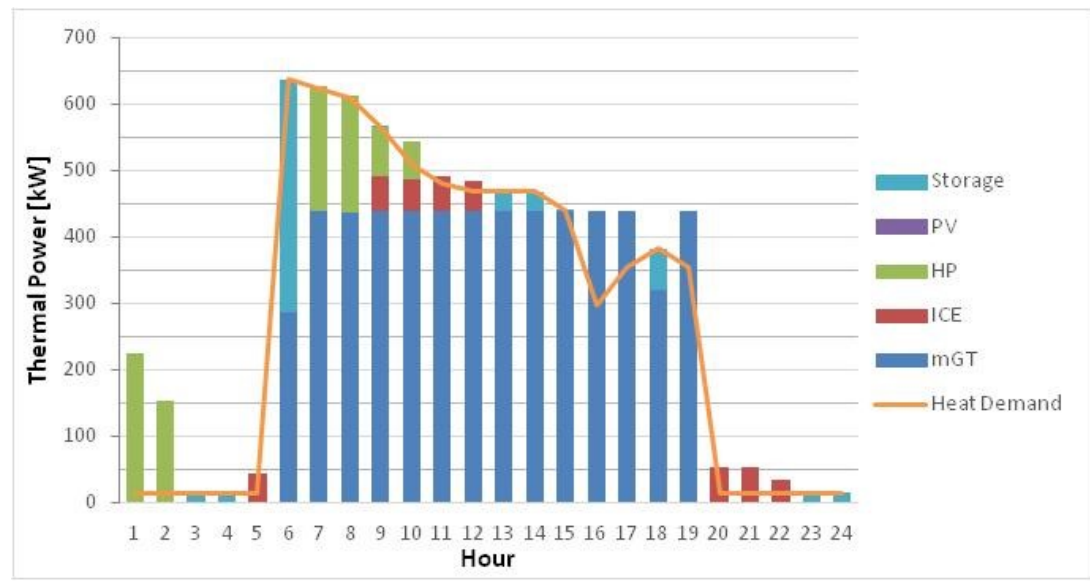

Fig. 5 Scenario B - Winter Time typical Electrical (Above) and Thermal (below) Demand)
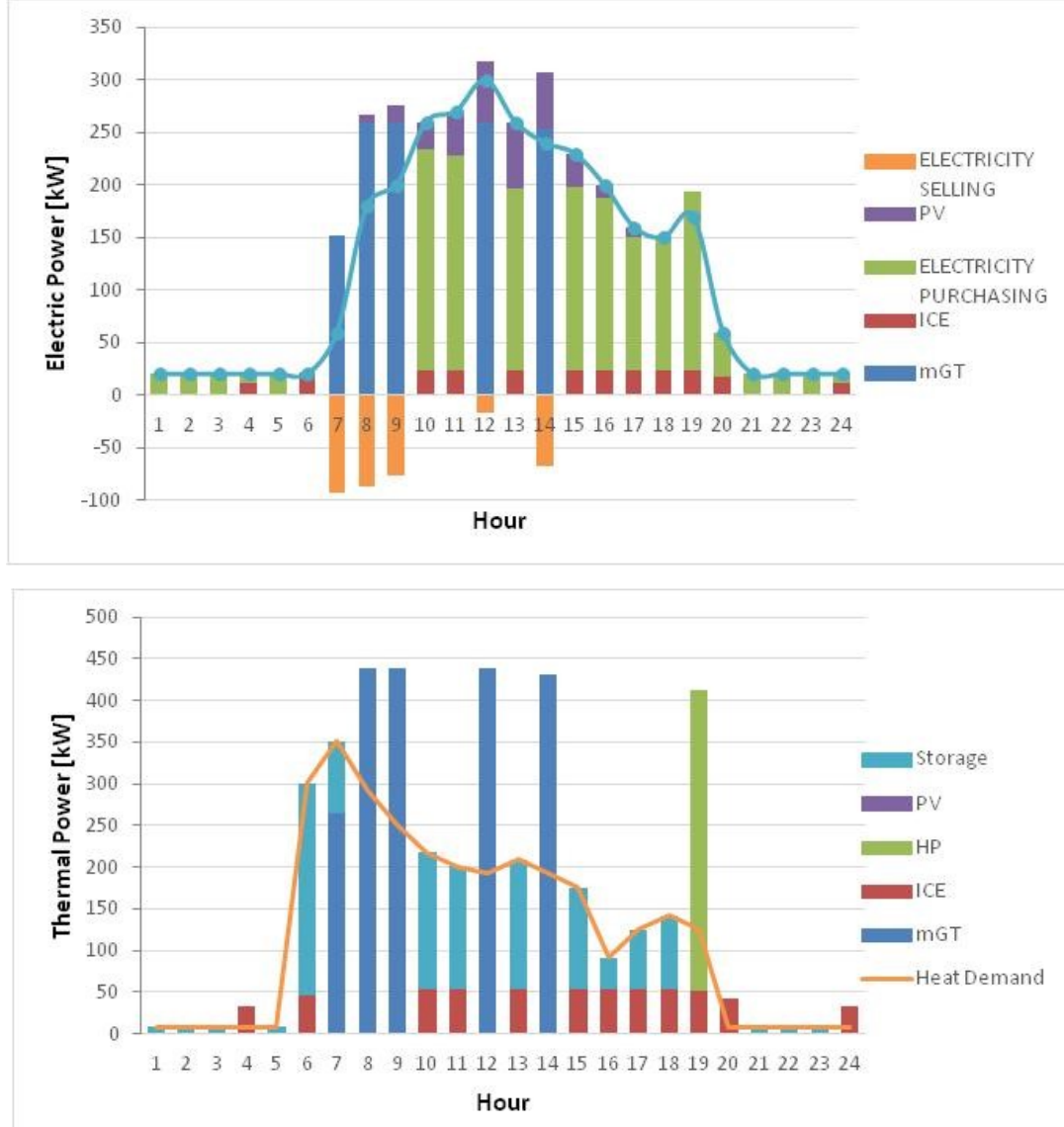

Fig. 6 Scenario B - Summer Time typical Electrical (Above) and Thermal (below) Demand) 


\section{Energetic and economic comparison}

In order to have a complete overview of the role of a heat pump in a polygenerative district, a comparison of the two configurations was performed from the energetic and economic point of view, underlining the differences in terms of energy consumption and savings (gas purchasing and electricity exchange with the national grid). In Table 1, the data related to the gas and electrical energy consumptions in the analysed cases are reported.

One of the most relevant saving is the significant reduction of the natural gas consumption due to the replacement of the boiler with the HP (about -16\%). On the other hand, as the heat pumps are electrical devices, the electrical energy brought from the grid increase of about $21 \%$. This increase is partly compensated by the increasing of the overall CHP production which allows a larger selling to the National grid.

Table 1 Energy comparison

\begin{tabular}{|l|c|l|c|}
\hline & & $\begin{array}{l}\text { Case A } \\
\text { (Boiler 500) }\end{array}$ & $\begin{array}{c}\text { Case B } \\
\text { (HP 350) }\end{array}$ \\
\hline Electricity purchasing from the grid & {$[\mathrm{kWh}]$} & $317.441,6$ & $383,834(+20.8 \%)$ \\
\hline Electricity selling to the grid. & {$[\mathrm{kWh}]$} & $27.897,58$ & $58,864(+114.8 \%)$ \\
\hline Natural Gas Consumption & {$[\mathrm{kg}]$} & $153.607,6$ & $129,430(-15.7 \%)$ \\
\hline Yearly Operating Period (Boiler or HP) & {$[\mathrm{h}]$} & 506 & $814(+60.9 \%)$ \\
\hline
\end{tabular}

One of the main advantages of installing the HP is that this device can exploit the electric overproduction of PV or CHP, allowing them to operate at nominal conditions more frequently, increasing their global efficiency. It is important to remember that the yearly operating time of the SPM is 6240 hours, as in the weekend the campus is closed, and the SPM is not operative.

In Table 2, the number of operating hours at high and low efficiency (at partial load lower that $80 \%$ ) are reported for both the mGT and ICE in the different cases. The installation of a HP allows for an average increase of the high efficiency functioning (partial load higher than $80 \%$ ) of about $20 \%$ for both the mGT and ICE. The difference in the overall number of operating hours of the mGT and the ICE is related to a different approach in managing the heat demand, which is the main guideline like in all the CHP plants. In fact, the introduction of a heat pump guarantees a better exploitation of the thermal energy storage, favouring the use of the mGT at higher load, as low heat demand periods are satisfied by the storage or by the heat pump itself, replacing the thermal contribution of the internal combustion engine.

Table 2 Operation for CHP devices

\begin{tabular}{|c|c|c|c|}
\hline \multirow{2}{*}{ Unit } & & $\begin{array}{c}\text { Case A } \\
\text { (Boiler 500) }\end{array}$ & $\begin{array}{c}\text { Case B } \\
\text { (HP 350) }\end{array}$ \\
\hline \multirow{2}{*}{ mGT } & High Efficiency operation $[\mathrm{h}]$ & 1232 & $1518(+23.2 \%)$ \\
\cline { 2 - 4 } & Low Efficiency operation $[\mathrm{h}]$ & 550 & $132(-76.4 \%)$ \\
\hline \multirow{2}{*}{ ICE } & High Efficiency operation $[\mathrm{h}]$ & 3058 & $2200(-26.2 \%)$ \\
\hline
\end{tabular}




\begin{tabular}{|l|l|l|l|}
\hline & Low Efficiency operation [h] & 770 & $704(-8.6 \%)$ \\
\hline
\end{tabular}

The introduction of a heat pump into the SPM has an impact both on the energy management and on the economics of the system. Table 3 presents a yearly variables cost and revenues for the SPM in the two configurations. For the economic analysis, the following assumptions were considered:

- The natural gas cost is assumed equal to $0.88 € / \mathrm{kg}$, which represents the cost for domestic and commercial use in Italy [16], inclusive of taxes;

- The price of electricity sold to the grid is assumed equal to $0.08 € / \mathrm{kWh}$, which represents a typical market price for the low voltage Italian scenario, as reported in [16]. The purchasing price from the grid is $0.20 € / \mathrm{kWh}[17]$;

- Price of electrical and thermal energy sold to users is assumed equal to $0.17 € / \mathrm{kWh}$ and $0.08 € / \mathrm{kWh}$, respectively;

Plant life is assumed equal to 20 years, depreciation time equal to 10 years and inflation rate equal to $3 \%$. Basing on thermal and electric demand curves, W-ECoMP calculates the best operating strategy.

Thanks, the installation of the HP, in case B total annual cost are reduced of about $3 \%$, the annual revenues increases of about $1 \%$ and the net income per year results $26 \%$ higher.

According to these results, a further investigation on the possibility to install an air-to-water heat pump (or other kinds of heat pump technology, suitable to the environmental location) instead of a natural gas boiler to manage heat demand peaks, can represent a worthy solution from both the energy efficiency and economic standpoints.

On the other hand, the discrepancy of investment cost between boiler and heat pump technology is significant and may increase the payback period of the whole plant. For this reason, characteristics, performances and dimensions of the heat pump system has to be carefully investigated and defined before installation.

Table 3 Economic results

\begin{tabular}{|l|c|c|}
\hline & Case A (boiler 500) & Case B (HP 350) \\
\hline Capital Cost of the Generator & $\mathbf{4 5 0 0 0} €$ & $\mathbf{1 1 5 0 0 0} €$ \\
\hline & \multicolumn{2}{|c|}{ Variable Costs } \\
\hline - Manteinance & $10.000 €$ & $10.000 €$ \\
\hline$\bullet$ Electricity Purchasing from the Grid & $122.086 €$ & $103.543 €(-15,1 \%)$ \\
\hline Total Costs & $63.488 €$ & $76.766 €(+20,6 \%)$ \\
\hline & $195.574 €$ & $190.310 €(-2,7 \%)$ \\
\hline$\bullet$ Electricity sold to Users & Revenues & \\
\hline$\bullet$ Electricity sold to the Grid & $144.381 €$ & $144.381 €$ \\
\hline$\bullet$ Thermal Energy sold to Users & $2.231 €$ & $4.709,08 €(+114 \%)$ \\
\hline Total Revenues & $78.624 €$ & $78.624 €$ \\
\hline Net Income & $225.237 €$ & $227.715 €(+1,1 \%)$ \\
\hline
\end{tabular}

\section{Conclusions}


The goal of this study has been to evaluate the impact of heat pump introduction in a smart polygenerative grid in order to encourage power to heat schemes to store electric over production (PV, CHP...) via thermal energy. This research can be considered a preparatory work for H2020 ENVISION activities in which Savona Campus SPM acts as demosite and where UNIGE and RINA-C will study a specific HP+TES based power to heat integration scheme (at hardware and control strategy level) to maximise the exploitation of solar production (thermal and electric) of ENVISION building envelope energy harvesters. Thermo-economic optimization are crucial for energy district not only to evaluate the technoeconomic feasibility of new designs but also to present a preliminary overview of demand management towards the development of optimized controllers. In this sense this work present how HP+TES can play an effective role of "trait d'union" between thermal and electric demand management grids particularly in presence of CHP units which can operate more in close to nominal conditions and increase their annual global efficiency.

\section{References}

1. https://ec.europa.eu/clima/policies/international/negotiations/paris en - last access $1 / 7 / 2019$

2. https://ec.europa.eu/energy/en/topics/energy-strategy-and-energy-union/clean-energyall-europeans - last access 1/7/2019

3. R. Bahindir, I. Colak, G. Fulli, K. Demirtas, "Smart grid technologies and applications", Renew. Sust. Energ. Rev., 66, 499-516, (2016).

4. M. Lesko, W. Bujalski, K. Futyma, "Operational optimization in district heating systems with the use of thermal energy storage”, Energy, 165, 902-915, (2018).

5. S. Barberis, M. Rivarolo, A. Traverso, A.F. Massardo, "Thermo-economic analysis of the energy storage role in a real polygenerative district", J. Energy Stor., 5, 187-202, (2016).

6. L. Zhang, N. Gari, L.V. Hmurcik, "Energy management in a microgrid with distributed energy resources”, Energ. Convers. Manage., 78, 297-305, (2014).

7. www.tpg.unige.it - last access 1/7/2019

8. M. Rivarolo, A. Cuneo, A. Traverso, A.F. Massardo, "Design optimisation of smart poly-generation energy districts through a model based approach", Appl. Therm. Eng., 99, 291-301, (2016). 
9. M. Rivarolo, A. Greco, A.F. Massardo, "Thermo-economic optimization of the impact of renewable generators on poly-generation smart-grids including hot thermal storage", Energ. Convers. Manage., 65, 75-83, (2013). 